\title{
Alunos com síndrome rara na escola comum: um olhar fenomenológico-existencial ${ }^{1}$
}

\author{
Rogério Drago \\ Hiran Pinel \\ Universidade Federal do Espírito Santo
}

\section{Resumo}

Tem como objetivo principal entender como sujeitos que apresentam uma síndrome rara são vistos-existenciados pelos outros seres que os rodeiam. Para tanto, caracterizamos algumas síndromes raras que se fazem presentes nas escolas de ensino comum; uma breve discussão acerca da inclusão, escolarização e práticas pedagógicas desenvolvidas com sujeitos com deficiência e transtornos globais do desenvolvimento no contexto da escola comum. Por fim são apresentadas algumas discussões acerca da fenomenologiaexistencial, que conduziu o estudo, bem como a discussão dos dados coletados numa pesquisa de campo com foco numa criança com uma síndrome rara em processo de inclusão escolar.

Palavras-chave: Inclusão escolar. Síndromes raras. Fenomenologiaexistencial.

1. Este artigo é parte do relatório de estágio de Pós-Doutoramento realizado junto ao Programa de Pós-Graduação em Educação da Universidade Federal do Espírito Santo, sob a orientação do Prof. Dr. Hiran Pinel. Uma versão menos detalhada, com dados preliminares e que deu origem ao estudo de pós-doutoramento foi apresentada no III Congresso Internacional Educação Inclusiva e Equidade, realizado em outubro/novembro de 2013 em Almada - Portugal. 


\section{Children with rare syndromes in common schools: an existential-phenomenological look}

Its main objective is to understand how individuals who have a rare syndrome are seen by other beings around them. To do so, we include a characterization of a few rare syndromes that are present in common schools; and a brief discussion about inclusion, education and educational practices applied to individuals with disabilities and global developmental disorders in the context of the common school. Finally, we present some discussion of the existential phenomenology that led the study, as well as of the data collected in a field study, focusing on a child with a rare syndrome in a process of school inclusion.

Keywords: School inclusion. Rare syndromes. Existential phenomenology.

\section{El niño con síndrome raro en la escuela común: una mirada fenomenológica existencial}

Su principal objetivo es entender cómo las personas que tienen un raro síndrome son vistas por otros seres que las rodean. Para ello, caracterizamos algunos síndromes raros que están presentes en las escuelas comunes; una breve discusión acerca de la inclusión, la educación y las prácticas pedagógicas desarrolladas con las personas con discapacidad y los trastornos generalizados del desarrollo en el contexto de la escuela común. Finalmente, se ofrecen algunas discusiones de la fenomenología existencial, que dirigió el estudio, así como la discusión de los datos recogidos en un estudio de campo se centra en un niño con un síndrome poco frecuente en el proceso de inclusión escolar.

Palabras-clave: La inclusión escolar. Síndromes raros. La fenomenología existencial. 


\section{Introdução}

Iniciamos nossas discussões questionando: por que estudar processos inclusivos de crianças com síndromes raras? A resposta a esta questão pode ser dada de várias maneiras, porém a que nós assumimos é a de que a existência humana é complexa, única e, por que não dizer, paradoxal. Isso parece mera conclusão do óbvio, porém, ao refletirmos sobre as existências le o ser-sendo ser humanol de pessoas que apresentam características tão peculiares quanto as apresentadas por pessoas com síndromes raras ou mesmo com transtornos globais do desenvolvimento, somos levados a refletir que este ser se constitui/ está se constituindo pelo olhar e palavra cercada de múltiplas existências, que podem contribuir para que esse sujeito se veja e se perceba como parte ou não de um todo maior. Desse modo, estudar um sujeito tão único é tentar mostrar que somos diferentes, e é essa diferença que faz com que a existência humana seja algo tão mágico.

Neste sentido, este artigo tem como objetivo principal entender como sujeitos que apresentam uma síndrome rara são vistos-existenciados pelos outros seres que os rodeiam. Para tanto, caracterizamos algumas síndromes raras que se fazem presentes nas escolas de ensino comum; uma breve discussão acerca da inclusão, escolarização e práticas pedagógicas desenvolvidas com sujeitos com deficiência e transtornos globais do desenvolvimento no contexto da escola comum. Por fim, são apresentadas algumas discussões acerca da fenomenologiaexistencial, que conduziu o estudo, bem como a discussão dos dados coletados numa pesquisa de campo com foco numa criança com uma síndrome rara em processo de inclusão escolar.

\section{Algumas síndromes raras mapeadas}

0 que é uma síndrome? Será que os profissionais que atuam nas escolas comuns têm conhecimento do que é uma síndrome, bem como as principais características de algumas síndromes que foram mapeadas e que alguns alunos possuem? A primeira resposta é: síndrome é o conjunto de sinais ou sintomas provocados pelo mesmo organismo e dependentes de causas diversas que definem um conjunto de características do ser. A segunda é: temos percebido tanto em nossa atuação docente quanto no contexto dos estudos e pesquisas realizadas (Drago, 2012; 2013) que não. Muitas são as dúvidas e desconhecimentos por parte dos profissionais da educação acerca das características de pessoas com determinadas síndromes. Esse desconhecimento tem ocasionado, em muitos 
casos, um desrespeito ao direito à educação de pessoas que, por não apresentarem as mesmas características que a maioria da população, são deixadas à margem do processo de ensino-aprendizagem.

Diante do exposto, mas sem a pretensão de medicalizar e biologizar a educação, antes disso, possibilitar a problematização de ações e novos/outros possíveis ao processo de inclusão pela via do conhecimento das características do indivíduo como ser único em sua existência, que podem contribuir para o repensar e o incremento das práticas pedagógicas cotidianas, a partir das possibilidades do sujeito e não daquilo que ele não é capaz. Nesse tópico, apresentamos algumas síndromes identificadas, dentre as mais de 8.000 diagnosticas e catalogadas pelos indicadores médicos, que se fazem presentes no contexto comum da educação do Estado do Espírito Santo. (Drago, 2012; 2013)

Síndrome de Gilles de la Tourette - é uma síndrome neurológica caracterizada por tiques involuntários, reações rápidas, movimentos repentinos ou vocalizações que ocorrem repetidamente da mesma maneira. A maioria das pessoas acometidas é do sexo masculino; o início da síndrome geralmente se manifesta na infância ou juventude; os sintomas ocorrem involuntariamente; pode manifestar coprolalia - uso de palavras obscenas e/ou insultos, na mesma proporção dos tiques involuntários. Foi descrita pela primeira vez em 1825 por Jean Marc Itard e em 1885 foi estudada e apresentada ao meio médico-acadêmico pelo neurólogo francês Georges Albert Brutus Édouard Gilles de la Tourette. Os tiques podem afetar qualquer parte do corpo, porém acometem principalmente a face.

Síndrome de Edwards - é uma síndrome genética cromossômica lcromossoma 18); tem como características principais: hipertonia; estatura baixa; cabeça pequena, alongada e estreita; pescoço curto; orelhas baixas e mal formadas; problemas oculares; lábio leporino; maxilares recuados; pés virados para fora com o calcanhar saliente; acentuada má formação cardíaca; anomalias renais; deficiência mental moderada a severa, demonstrando, geralmente, comprometimento do sistema nervoso central. A esperança de vida é pequena, mas existem casos de pessoas que chegam aos 15 ou mais anos de idade.

Síndrome de Willians - caracterizada por problemas cardiovasculares, rostos com características semelhantes (aparência élfica), deficiência mental leve a moderada, dificuldade na leitura, na escrita e na matemática e um gosto exacerbado por música. Esta síndrome partilha algumas características com o autismo, apesar de as crianças possuírem uma facilidade de relacionamento interpessoal acima da média. Características comuns: baixo peso ao nascer, dificuldade na alimentação nos primeiros dias, problemas cardiovasculares, cólicas nos primeiros meses, atrasos no desenvolvimento, menor volume cerebral, personalidade extremamente sociável, menor tamanho que o esperado para a 
idade, baixo timbre de voz, traços faciais característicos.

Síndrome de Kabuki - foi descrita inicialmente no Japão, em 1981, como um distúrbio raro sem causa conhecida; pálpebra inferior reversa; fenda palpebral alongada; sobrancelhas arqueadas; cílios longos; esclera azul; ponta nasal voltada para baixo; palato alto/fendido, fenda labial; orelhas disfórmicas; fístulas préauriculares; anomalias dentárias; problemas neurológicos; hipotonia; problemas alimentares; convulsões; microcefalia; anomalias visuais; déficit no crescimento; deficiência mental leve a moderada; perda auditiva em mais de $50 \%$ dos pacientes; atrasos no desenvolvimento da linguagem. Por se tratar de uma síndrome de baixa prevalência, o diagnóstico permanece baseado nas características da síndrome.

Síndrome de Progéria-éuma síndrome genética extremamente rara queacelera o processo de envelhecimento em cerca de sete vezes à taxa normal; a expectativa média de vida das pessoas é de 14 anos para meninas e 16 para meninos; esta síndrome afeta 1 entre 8 milhões de crianças. Cerca de 150 casos foram relatados desde sua descoberta; o diagnóstico é fundamentalmente clínico. Os sujeitos com Progéria não apresentam deficiência mental. Principais características: artrose, baixa estatura ou nanismo, cabelo rarefeito ou ausente, clavícula ausente ou anormal, dificuldades na alimentação no lactante, envelhecimento prematuro, erupção tardia dos dentes, face estreita, fenótipo emagrecido, hipoplasia terminal dos dedos, luxação do quadril, pele fina, puberdade tardia, sobrancelhas ausentes, unhas finas, choro anormal, lábios finos, osteoporose.

Síndrome Cri du Chat (miado de gato) - os recém-nascidos apresentam o choro fraco semelhante ao miado de gato; os bebês apresentam baixo peso ao nascimento devido a uma deficiência de crescimento intrauterino; microcefalia; face arredondada; aumento da distância entre os olhos; estrabismo; desenvolvimento reduzido da mandíbula; orelhas abaixo da linha do nariz; malformações dentárias; luxação de quadris; podem ocorrer problemas cardíacos e/ou renais; pé torto congênito; na maioria dos casos tônus muscular diminuído; apresentam dificuldade na alimentação; peso e estatura reduzidos; deficiência mental moderada a severa; atraso no desenvolvimento da linguagem; dificuldade de concentração/atenção; agitação; irritabilidade; sono agitado. É uma síndrome cromossômica - cromossomo 5.

Síndrome de Turner - ocorre somente em mulheres. São as que apresentam um cariótipo com 44 cromossomos autossômicos e apenas um cromossomo sexual X. Esta síndrome causa $18 \%$ dos casos dos abortos espontâneos cromossomicamente anormais. Características principais: baixa estatura, disgenesia gonadal, fáceis incomuns típicas, pescoço alado, linha posterior de implantação dos cabelos baixa, tórax largo com mamilos amplamente espaçados, frequência elevada de anomalias renais e cardiovasculares. Geralmente apresentam atraso na primeira 
menstruação, além de déficit de percepção espacial e visual-motor, tendo dificuldades gerais em tarefas não verbais. A cada 2500 nascimentos uma criança apresenta o fenótipo característico da síndrome de Turner. Podem levar uma vida absolutamente normal.

Síndrome de Klinefelter - é a causa mais frequente de hipogonadismo e infertilidade em indivíduos do sexo masculino. As pessoas com essa síndrome, pessoas do sexo masculino, têm um cromossomo $X$ adicional, estatura elevada, desenvolvimento do tecido mamário e testículos pequenos; podem apresentar déficit auditivo. Têm uma esperança de vida normal. Podem apresentar atraso na linguagem, atraso motor e problemas escolares. Podem apresentar deficiência mental leve, moderada ou severa. Além disso, podem apresentar características como esterilidade, características masculinas incompletas, problemas sociais e/ou de aprendizagem, dificuldade de concentração, baixo grau de paciência, baixa autoestima, baixo grau de paciência, dificuldade em despertar pela manhã, preferência por jogos calmos; muitas vezes detecta-se somente na fase da puberdade.

Síndrome de West - é um tipo raro de epilepsia que se inicia normalmente no primeiro ano de vida, mas pode surgir em idade mais avançada, sendo o sexo masculino o mais acometido. É uma síndrome neurológica, detectada por meio de exames de ressonância magnética. Ou seja, é uma encefalopatia epiléptica degenerativa com finalização em uma deterioração psicomotora. Caracterizase por contrações breves, maciças, simétricas, com predominância de flexão da cabeça e do tronco. Contrações que podem variar de 03 a 50, havendo descrições de até um número superior de ataques ou contrações. Podem acontecer tanto no sono quanto acordados. Quase sempre há perda de cunho neuropsíquico da criança; há possibilidade de remissão total de espasmos infantis; não há confirmação científica de remissão definitiva para os casos mais graves; podem vir a apresentar quadro de deficiência intelectual; há necessidade de estimulação para diminuição do grau de comprometimento intelectual; pode afetar o sistema locomotor.

Síndrome de Patau - apresentam problemas no sistema nervoso central, severos e associados à deficiência mental; possuem lábio leporino e palato fendido; problemas característicos dos padrões dérmicos, além de problemas cardíacos, viscerais e da genitália; anomalia do cromossomo 13. Estima-se que somente $5 \%$ dos casos que nascem vivos sobrevivem mais de 3 anos; está associada à idade materna avançada; as orelhas são malformadas e baixamente implantadas, os olhos são pequenos e extremamente afastados, podendo os globos oculares chegar a ser ausentes; apresentam, ainda, baixo peso, microcefalia e testa achatada, queixo pequeno, problemas na face média, pescoço curto, genitais 
externos anômalos e deficiência mental severa.

Síndrome de Noonan - também chamada de síndrome de Turner masculina, pode ocorrer tanto no sexo masculino quanto no feminino; caracterizada por baixa estatura, dimorfismo craniofacial, pescoço curto, problemas cardíacos e esqueléticos e criptorquidismo (falha na descida do testículo para a bolsa escrotal); alterações ósseas, má oclusão dentária, implantação baixa das orelhas, base nasal larga, pescoço alado, problemas de audição e oftalmológicos. Pode trazer déficit de desenvolvimento na infância, atraso motor, atraso na linguagem e dificuldade de aprendizado, sendo que a deficiência leve a moderada é encontrada em $35 \%$ dos casos.

Síndrome de Rett - é uma síndrome que causa problemas de ordem neurológica, acometendo quase que exclusivamente crianças do sexo feminino, causando deficiência mental severa e múltiplas deficiências. Compromete progressivamente as funções motora e intelectual e provoca distúrbios de comportamento e dependência. No caso típico, a menina desenvolve-se de forma aparentemente normal entre 8 e 18 meses de idade, depois começa a mudar seu padrão de desenvolvimento. Ocorre uma regressão dos ganhos psicomotores, a criança torna-se isolada e deixa de responder e brincar. 0 crescimento craniano, até então normal, demonstra clara tendência para o desenvolvimento mais lento, ocorrendo microcefalia adquirida. Aos poucos, deixa de manipular objetos, surgem movimentos estereotipados das mãos (contorções, aperto, bater de palmas, levar as mãos à boca, lavar as mãos e esfregá-las), culminando na perda das habilidades manuais.

Síndrome de Crouzon - é uma síndrome rara de origem genética, caracterizada por comprometer o desenvolvimento do esqueleto craniofacial; existem estudos que levantam a hipótese de essa síndrome estar relacionada com a idade paterna avançada. Encontra-se no grupo das craniossinostoses, que apresentam como característica a fusão sutural prematura de forma isolada ou em associação com outros problemas. Pode também estar presente nessa síndrome relativa deficiência mental. Vários fatores encontram-se relacionados com seu desenvolvimento neuropsicológico, como: a existência da hipertensão intracraniana; fatores que dizem respeito ao ambiente no qual a criança encontra-se inserida e os estímulos que ela recebe podem representar um papel fundamental em seu desenvolvimento; o desenvolvimento morfológico do sistema nervoso central pode apresentar distintos tipos de alterações, como malformações ventriculares. Pode apresentar problemas visuais em função da protuberância do globo ocular e problemas na articulação da linguagem oral.

Síndrome de Apert - é uma síndrome genética e pode ser herdada de um dos pais ou pode ser uma mutação nova. Ocorre em aproximadamente 1 para 160.000 
a 200.000 nascidos vivos. Desconhecem-se as causas que produzem esta mutação. A síndrome de Apert é caracterizada por má formação específica do crânio, terço médio da face, mãos e pés, além de diversas alterações funcionais que variam muito de um indivíduo a outro. 0 crânio tem fusão prematura e é incapaz de desenvolver-se normalmente; o terço médio da face lárea da face que vai da órbita do olho até o maxilar superiorl parece retraída ou afundada; os dedos das mãos e dos pés têm fusão em variados graus. 0 crescimento anormal do crânio e face na síndrome de Apert produz seus principais sinais e sintomas: a cabeça tem aspecto longo, com uma testa alta; olhos encovados, muitas vezes com mau fechamento das pálpebras; um rosto meio afundado; desenvolvimento intelectual baixo Ina maioria das crianças com a síndrome); apneia obstrutiva do sono; repetidas infecções no ouvido; perda auditiva.

Síndrome Cornélia de Lange - síndrome caracterizada por deficiência do crescimento, deficiência mental moderada ou severa, baixa estatura, um choro tipo rosnar baixo, orelhas pequenas, pescoço em cadeia, boca de carpa, ponte nasal diminuída, sobrancelhas atrofiadas se encontrando no meio, malformações das mãos; recém-nascidos pequenos, com baixo peso, apresentam uma microcefalia e características faciais particulares, que se misturam com os traços herdados da sua própria família; pestanas longas, nariz pequeno, cara redonda, lábios finos e ligeiramente invertidos. As mãos e os pés são pequenos, o quinto dedo está geralmente encurvado e, por vezes, as crianças apresentaram uma membrana interdigital entre o segundo e o terceiro dedo dos pés. A síndrome caracteriza-se também pela presença de um atraso de linguagem, deficiência mental, anomalias cardíacas, intestinais, refluxos gastresofágicos, problemas visuais e auditivos e dificuldades de alimentação. As pessoas com esta síndrome podem registrar uma falta de sensibilidade à dor ou uma sensibilidade táctil mais acentuada.

Síndrome de Rubisntein-Taiby - pode acometer tanto meninas quanto meninos, indistintamente. Acredita-se que seja genética e originada por uma alteração no braço curto do cromossomo 16. As principais características são: baixa estatura, nariz pontiagudo, orelhas ligeiramente deformadas, palato (céu da bocal curvado, cabeça pequena, sobrancelhas grossas ou curvadas, polegares largos, dedões dos pés largos e grossos, olhos inclinados para baixo com fendas que são chamadas de antimongolóides, marca de nascença vermelha na testa, articulações hiperextensíveis, pelve pequena e inclinada, excesso de cabelos, dentre outras. Nos meninos pode ocorrer criptorquidia lquando os testículos não descem para a bolsa escrotal). Podem apresentar problemas de linguagem e deficiência mental leve a moderada. As pessoas têm normalmente caráter amigável e alegre, são muito felizes e bastante socializadas. Costumam ter um sorriso como se estivessem fazendo careta. Têm o costume de tocar qualquer 
coisa e gostam de manipular instrumentos e eletrônicos. Gostam de livros, água, pessoas e são muito sensíveis a qualquer forma de música.

Síndrome do X Frágil - essa síndrome representa a primeira causa de deficiência intelectual/cognitiva herdada, e sua incidência é de cerca de 1:4000 em homens e 1: 6000 em mulheres, o que pode pressupor que não se caracteriza como uma síndrome rara, ou seja, é a segunda causa genética de deficiência mental, depois da síndrome de Down. Em relação às características físicas dos sujeitos que possuem a síndrome do x frágil, que podem se tornar mais evidentes podemos citar: face alongada; orelhas grandes e em abano; mandíbula saliente, testículos aumentados. Além dessas, outras características como: diminuição da tonicidade muscular, comprometimento do tecido conjuntivo (tecido do corpo que tem por finalidade encher, sustentar e proteger), pés planos, céu da boca alto, estrabismo, escoliose, calos nas mãos, dentre outras peculiaridades.

Síndrome de Angelman - dentre as manifestações clínicas podem estar presentes a deficiência física e mental; atraso no desenvolvimento do perímetro cefálico; ausência da fala com sinais de compreensão; sinais de hipotonia, apresentando também desenvolvimento motor deficitário; problemas de movimento e de equilíbrio; hiperatividade e déficit de atenção; risadas explosivas e frequentes que não estão diretamente ligadas a emoção, mas sim a expressões motoras; personalidade facilmente excitável; crises convulsivas; dificuldades para dormir; transtorno do espectro autista; hipopigmentação da pele e cabelos; hipersensibilidade ao calor e estrabismo. A incidência da síndrome de Angelman está estimada em torno de 1 caso para cada 15 a 30 mil nascimentos. Seu diagnóstico só pode ser confirmado a partir do estudo genético detalhado, além da investigação das manifestações clínicas.

As síndromes apresentadas são apenas um recorte daquilo que nos tem incomodado no contexto educacional referente ao processo de inclusão/ exclusão educacional pelo qual muitos sujeitos têm passado em seu processo de escolarização. Chamamos a atenção para o fato de que as características descritas nas poucas síndromes apresentadas precisam ser levadas em consideração para repensarmos o(s) modo(s) como percebemos o(s) outro(s) ao nosso redor. Afinal, é esse olhar (ou não olhar) que pode (ou não) conduzir o fazer docente. Refletir sobre tais características, e a partir delas planejar ações inclusivas não excludentes, é o que almejamos; daí a necessidade de se repensarem o processo de inclusão, escolarização e as práticas pedagógicas para sujeitos concretos que se constituem nas e pelas relações existenciais (e nesse bojo, fenomenológicas) com os demais sujeitos que compõem o contexto macrossocial (sociedade) e microssocial (escola). 


\section{De modo breve... inclusão, escolarização e práticas pedagógicas}

Pensar a chegada de pessoas com deficiência ou transtornos globais do desenvolvimento nas salas comuns da educação básica é um processo que tem deixado ainda (em pleno século XXI) muitos profissionais da área educacional angustiados. Essas angústias perpassam fatores que vão desde a falta de formação, passando por questões de cunho estruturais (principalmente as relacionadas à infraestrutura dos ambientes escolares), até o modo como pensam o planejamento e a execução das aulas. Temos percebido que muitos profissionais da área da educação ainda não têm claro para si que o sujeito, independentemente de quaisquer características, tem direito a usufruir da escola comum, como está preconizado pelos documentos legais que regem a educação no Brasil (Brasil, 1988; 1996; 2008; dentre outros). Mas, para além de questões legais, a inclusão escolar também passa por uma questão subjetiva, própria do "sujeito professor", em íntima associação ao modo como se vê e se percebe como um dos sujeitos do processo educativo.

Nesse contexto, enfatizamos que a inclusão de pessoas com deficiência e com transtornos globais do desenvolvimento nas salas comuns da escola básica, conforme preconizam alguns documentos legais (Brasil, 2008; 2009) e alguns dos principais estudiosos nacionais da área (Prieto, 2006; Mendes, 2002; Baptista, 2006; Beyer, 2006; dentre outros), é um processo que ganha força a partir da Declaração de Salamanca, em 1994, e se estende até hoje como uma bandeira que tem por objetivo garantir a premissa de que a educação é um direito de todos e dever do Estado. Esse 'todos' envolve todas as pessoas que estejam fora da escola ou dela e de seus processos alijados, ou mesmo aqueles que estão na escola - como os sujeitos anteriormente descritos, mas que, por motivos biológicos, deixam de se apropriar dos processos educativos por crenças (errôneas) de que não aprendem por se distanciarem dos padrões de normalidade impostos pela sociedade.

Portanto, entendemos que, de acordo com Beyer,

A educação inclusiva caracteriza-se como um novo princípio educacional, cujo conceito fundamental defende a heterogeneidade na classe escolar, como situação provocadora de interações entre crianças com situações pessoais as mais diversas. Além dessa interação, muito importante para o fomento das aprendizagens recíprocas, propõe-se e busca-se uma pedagogia que se dilate frente às diferenças do alunado. (Beyer, 2006, p. 73)

Esse novo princípio educacional sinaliza a necessidade de repensarmos as práticas pedagógicas e os processos de escolarização para pessoas que hoje retornam às escolas, uma vez que durante séculos estiveram à margem tanto da 
sociedade quanto das escolas e de suas ações, como mostram estudos de Mazzotta (2001) e Jannuzzi (2006). A literatura atual que trata da educação da pessoa com deficiência tem enfatizado que existem ainda muitas armadilhas para que a escola inclusiva deixe de ser mera proposição legal e passe a existir de verdade. Entre essas armadilhas podemos destacar duas: as práticas supostamente inclusivas que muitas vezes excluem as pessoas com deficiência do contexto educacional e os materiais utilizados para o desenvolvimento da ação pedagógica (Drago, 2011). Essas práticas e esses materiais muitas vezes simplificam os conteúdos curriculares, fazendo com que, para a pessoa com deficiência, seja criado um pseudocurrículo, ou outro currículo, diferente, minimizado, quando na verdade o que se espera é que esses alunos se apropriem do mesmo currículo com variadas propostas de trabalho. Ou seja, o que nos importa é o modo, os procedimentos, as ferramentas que esse sujeito utiliza para se apropriar dos conhecimentos produzidos social e culturalmente.

Quando pensamos na proposta de uma escola inclusiva, que leve em consideração as particularidades, possibilidades e peculiaridades de cada sujeito como mola propulsora da ação pedagógica, temos em mente que a inclusão requer a quebra de cristalizações educacionais que fazem com que tantas pessoas sejam deixadas à margem do conhecimento escolar por apresentarem características que, muitas vezes, destoam daquilo que convencionalmente se tem como normal, acomodado, cristalizado. Ou seja, o que se pretende enfatizar é que as pessoas com deficiência ou transtornos globais do desenvolvimento deixem de ser vistas como coisas, objetos estáticos e passem a ser vistas como sujeitos cognoscentes, aprendentes, existenciais, únicos.

A inclusão, a escolarização e as práticas pedagógicas que assegurem 0 sucesso educacional de todos os sujeitos pressupõem o reconhecimento de todas as diferenças que contribuem para um novo modo de organização do sistema educacional, que vai muito além da mera escola e da sala de aula em si, sem subdivisões, sem guetos. Esse entendimento de escola inclusiva requer, necessariamente, que se efetive no contexto educacional a ideia de ambientes dinâmicos, ricos, envolventes para estimular todos os alunos. Logo, o que se tem em mente é que a escola comum seja capaz de dar conta de todas as especificidades e peculiaridades de todos os seus sujeitos, de modo que estes, por sua vez, não sejam confinados em salas especiais, muitas vezes especiais somente no nome, mas excludentes, pois deixam de fora do contexto das relações sociais grupos de pessoas, no interior de escolas que se dizem inclusivas.

A escola inclusiva precisa ser vista como aquela que se direciona para um ensino que, além de reforçar os mecanismos de interação solidária e os procedimentos cooperativos, auxilia o ser humano a se ver e se perceber como parte de um todo 
que independe de suas características físicas. Além disso, salientamos que as práticas pedagógicas assumidas numa perspectiva inclusiva são esse elementochave da transformação da escola, pois acreditamos que são as mudanças de postura, de enxergar, de perceber, de falar, de agir, de ouvir, de planejar, de avaliar, de por em prática o currículo escolar, dentre outras aç̃ões, que possibilitarão a transformação do ser humano e da sociedade, para além da legislação.

No que tange às síndromes raras, como Rett, Willians, Rubinstein-Taybi, Noonan, Klinefelter, Turner, Tourette, dentre outras, temos observado em vários estudos (Drago, 2011; 2012; 2013) que a proposta de educação inclusiva, que vê o indivíduo como sujeito da ação pedagógica, tem se efetivado de modo ainda tímido e incipiente. Além disso, não conhecemos estudos que tenham se debruçado sobre as existências desses sujeitos como seres que também produzem história e cultura a partir de uma vertente fenomenológica-existencial.

Entendendo que a inclusão escolar de sujeitos únicos e as práticas educacionais inclusivas são modos de reconhecer no sujeito suas potencialidades para além de características biologizantes, nos próximos itens apresentamos um breve relato de parte de um estudo que teve como foco entender como sujeitos que apresentam uma síndrome rara são vistos-existenciados, no processo de inclusão, pelos outros seres que os rodeiam no contexto da escola comum.

\section{Considerações metodológicas}

Este estudo, vale salientar, é de natureza qualitativa, uma vez que esta natureza, sem desconsiderar a importância das pesquisas quantitativas, nos permitirá estabelecer uma relação dinâmica, particular, contextual e temporal entre nosso interesse de estudo, a síndrome rara e a criança que será sujeito do estudo. Além disso, no estudo de natureza qualitativa, de acordo com Michel (2009, p. 37), “o ambiente da vida real é a fonte direta para obtenção dos dados, e a capacidade do pesquisador de interpretar essa realidade, [...], é fundamental para dar significado às respostas".

Nessa direção, assumindo a natureza qualitativa como orientadora do estudo, elegemos como metodologia de pesquisa a fenomenologia-existencial. A escolha por tal metodologia se deu pelos seguintes argumentos (Gil, 1994):

a) a fenomenologia não se preocupa com algo desconhecido que se encontre atrás do fenômeno, só visando ao dado, sem querer decidir se este dado é uma realidade ou uma aparência: haja o que houver, a coisa está aí.

b) consiste em mostrar o que é dado e em esclarecer este dado. Não explica mediante leis nem deduz a partir de princípios, mas considera imediatamente 0 
que está presente à consciência, o objeto.

c) a adoção do método fenomenológico-existencial implica uma mudança radical de atitude em relação à investigação científica lou seja, tudo o que a inclusão também pressupõe - uma mudança radical de atitude em face ao outro e aos processos educacionais).

d) possui a proposta de esclarecer sobre o ser do homem, revelando suas estruturas existenciais e abandonando qualquer teoria desvinculada do verdadeiro sentido da existência. Ou seja, tal abordagem tenta alcançar o sentido da existência humana em sua totalidade, sem tomar a priori aspectos definidores de cada indivíduo, que possam desfigurar o fenômeno que se mostra. (cepcariri.blogspot. com.br)

Segundo Pinel (2004, p. 01),

[...] a pesquisa fenomenológica está interessada em descrever a vivência subjetiva (na objetividade do mundol do outro, de acordo com o outro, isto é, descrever o vivido pelo outro, a experiência do outro tal qual ele a vive, de acordo total com sua linguagem, ou expressões corporais, entre outros.

\section{Além disso, salientamos que}

[...] a meta em uma pesquisa fenomenológica é chegar às essências dos fenômenos que se mostram ali no imediato vivido. 0 objeto da pesquisa fenomenológica é o próprio fenômeno tal qual se representa na consciência (aquilo que aparece), e não é o que o sujeito pensa ou afirma a seu respeito. 0 foco é estudar tal qual o sujeito vive 0 fenômeno. Na relação pesquisador e pesquisado a 'coisa' é vivida como indissociada, imbricada - sujeito e objeto inter-relacionados. Por isso dissemos que a fenomenologia é uma atitude, uma postura, um clima, uma vontade de sentido de compreender - e não de ficar explicando. (Pinel, 2011)

A coleta de dados, por sua vez, assumindo essa característica, se deu por meio de: observação participante do/no cotidiano escolar, em que o pesquisador assumiu a característica de mais um sujeito do processo, atuando junto aos outros sujeitos; entrevistas e conversas informais com os membros da comunidade escolar; e análise documental, no sentido de levantar estudos que envolvam tanto a síndrome em questão, quanto os processos inclusivos e a metodologia fenomenológica-existencial.

Portanto, diante do exposto, destacamos que

Produzir pesquisa fenomenológico-existencial também exige (nos modos mesmos de ser sendo...) uma consciência crítica, mas sem perder a ternura jamais - sua poética que se dá nesse mesmo mundo. Por isso acreditamos, pelo menos por ora, que há uma 
singularidade, mesmo que seja na pluralidade dos 'modos de ser sendo si mesmo no cotidiano do mundo'. (Pinel, 2005, p. 21)

Entendendo, então, o ser humano como único em sua existência, que se desenvolve a partir do olhar e da palavra (para além da fala) do outro, desenvolvemos nosso estudo num centro municipal de educação infantil da cidade de Vitória-ES. A escolha por esta etapa da educação básica e por este Município se deu pelo fato de que, nesta etapa e neste Município, existia uma criança regularmente matriculada, no ano de 2013, com uma das síndromes brevemente descritas anteriormente Rubisntein-Taiby, que é muito rara. Assim, foram sujeitos do estudo: uma criança com a síndrome, a professora que a acompanhou em 2012, a professora de 2013, a mãe da criança e a professora do Atendimento Educacional Especializado.

\section{0 olhar fenomenológico-existencial para a criança com síndrome de Rubinstein-Taybi: o que o outro nos diz?}

A Síndrome de Rubinstein-Taybi pode ser caracterizada como uma síndrome rara, pois acomete cerca de 1 em cada 300.000 crianças nascidas vivas, o que pode ser uma das causas do seu desconhecimento por grande parte de professores, pesquisadores e sociedade de modo geral.

De acordo com dados encontrados (Assis, 2011; ARTS, 2013; dentre outros), não existe ainda uma causa comprovada para essa síndrome, porém acredita-se que seja genética e originada por uma alteração no braço curto do cromossomo 16.

Essa síndrome foi descrita pela primeira vez em 1963,

[...] quando os autores que a nomearam com seus sobrenomes chamaram a atenção para as semelhanças das manifestações clínicas e dos traços físicos apresentados em sete crianças portadores de deficiência mental, anomalias faciais e dígitos largos. (Martins; Bueno; Fioravanti, 2003, p. 2)

De modo geral, as principais características físicas detectadas nos sujeitos que apresentam tal síndromesão: baixa estatura, nariz pontiagudo, orelhas ligeiramente deformadas, palato (céu da boca) curvado, cabeça pequena, sobrancelhas grossas ou curvadas, polegares largos, dedões dos pés largos e grossos, olhos inclinados para baixo com fendas que são chamadas de antimongolóides, marca de nascença vermelha na testa, articulações hiperextensíveis, pelve pequena e inclinada, excesso de cabelos, dentre outras. Nos meninos pode ocorrer criptorquidia (quando os testículos não descem para a bolsa escrotal), porém, pode afetar tanto 
meninas quanto meninos, indistintamente.

Além dessas características que são facilmente observáveis externamente, alguns problemas internos podem ser detectados nos sujeitos com a síndrome.

Problemas típicos depois do nascimento incluem dificuldades na alimentação, infecções respiratórias, infecções de ouvido, infecções de olho e anormalidades como obstrução de tubo lacrimal, excesso de mucosa e às vezes diarreia [...]. Problemas oculares, anomalias cardíacas, anormalidades vertebrais, refluxo gastroesofágico e vômitos, abnormalidades de rim, problemas ortopédicos são frequentemente encontrados em indivíduos com síndrome de Rubinstein-Taybi. (Campos, 2003, p. 1)

Os estudos analisados também deixam claro que a pessoa com a síndrome tem deficiência intelectual que pode variar de grau, ou seja, "essas crianças apresentam, com bastante frequência, nível intelectual rebaixado e retardo no desenvolvimento neuropsicomotor e da linguagem". (Martins; Bueno; Fioravanti, 2003, p. 2)

No que tange ao diagnóstico, os estudos têm mostrado que este pode ser feito por meio de uma avaliação médica e física, além do uso de radiografias dos polegares e dos hálux (dedão dos pés) largos e grandes, assim como a análise de cromossomo. Os autores consultados também indicam que a síndrome não pode ser detectada intrauterinamente: seu diagnóstico, geralmente, se dá no parto ou mesmo nos primeiros anos de vida.

No que se refere ao desenvolvimento mental, linguístico e social, os estudos têm demonstrado que se trata de uma síndrome em que os sujeitos apresentam um comportamento bem peculiar.

Outros estudos salientam, ainda, que essas pessoas tendem a se adaptar a horários rotineiros e não gostam de atividades que envolvam grupos grandes e que emitam muitos barulhos. "Muitos indivíduos com síndrome de RubinsteinTaybi trabalham bem um-em-um ou em grupos de estrutura pequena". (Campos, 2003, p. 3)

Olhar um sujeito, que nosso estudo encara como sócio-histórico, com uma síndrome rara como a de Rubinstein-Taybi, na escola comum, vivenciando os processos educacionais e paradigmáticos conflituosos deste início de século é pensar que este sujeito se constitui a partir do olhar e da palavra (para além da fala) do outro. Ou seja, nos humanizamos “[...] na medida em que nos relacionamos com as coisas, com a natureza, com as pessoas, enfim, com a sociedade na qual vivemos" (Diogo; Maheirie, 2007, p. 140). Além do exposto, vale salientar que

A maior contribuição da fenomenologia existencial à educação é a perspectiva que abre para a possiblidade de descrição, análise e reflexão da realidade vivida pelo 
aluno ao estar com os outros, professores e alunos, dando destaque à perspectiva da existencialidade humana, que se efetiva na complexidade do imediato e na/da vida psíquica. A fenomenologia existencial descreve as condições da existência que incluem o poder de fazer escolhas nos limites da facticidade humana e dos modos factuais de existir. (Martins; Bicudo, 2006, p. 55)

Nesse sentido, somos levados a crer que a criança com a síndrome, foco deste estudo, também produz cultura e conhecimento lao mesmo tempo em que se apropria da cultura e do conhecimento do(s) outro(s) ao seu redor) tanto na escola como fora dela, já que vive o ser-sendo no mundo rodeado por inúmeras outras identidades coletivas. Mas... e na escola? E no contexto formal/sistematizado de ensino? Como esse ser tão peculiar, tão único e raro (se é que existem pessoas que não são únicas e raras) é visto/se-vê/vem-sendo constituído?

Partindo dessas questões podemos salientar que

0 mundo-vida, com seus horizontes, constitui a estrutura do mundo, tanto dos alunos na escola como de qualquer ser-humano. Ser-no-mundo, no que se refere à educação, é viver um horizonte de livros, de sala de aula, de equipamentos escolares, de material escolar, de professores etc. Ao viver essa situação, não como num contexto de relações que significa apenas o ambiente imediato, mas como um encontro de horizontes, o aluno vive, também, o horizonte de sua família, de seus amigos, de seus colegas e de seus professores e, ainda, os horizontes do seu próprio mundo interno, ou seja, o mundo do si-mesmo, dos seus sentimentos e das suas disposições, das suas dúvidas e das suas certezas. (Martins; Bicudo, 2006, p. 54-55)

Ser-no-mundo, a partir daquilo que Martins, Bicudo (2006) e outros autores destacam, está associado também ao modo como me constituo nas/pelas relações que estabeleço tanto em minha vida pessoal quanto, como no caso deste estudo, profissional. A chegada de um sujeito não-sendo-para-mim-ainda no contexto escolar pode fazer com que se quebrem algumas cristalizaçõesengessamentos tidos como verdades, possibilitando uma revisão de ações docentes homogeneizadas:

Ser professora é algo mágico, alegre, que me faz aprender a cada dia mais o valor do ser humano. Acredito que, a cada início de ano, a cada turma que pego, são vidas que serão transformadas a partir das relações que iremos construir. Relações saudáveis, de amizade, de parceria, de afetividades, de respeito e de desenvolvimento. [...]. Em 2012 recebi uma criança que aparentava ter alguma síndrome. Nos seus primeiros dias de aula demonstrou um fascínio pela escola, por tantas cores e formas ao seu entorno. Mas não se expressava oralmente, nem participava da rodinha, apenas observava com muita atenção. Seus olhinhos brilhavam a cada música, história, caixa surpresa e/ou atividade trabalhada. Logo a mãe trouxe um laudo dizendo que esta criança apresentava uma síndrome chamada Rubinstein-Taybi, e não soube me explicar o que 
era. [...]. Então comecei a pesquisar para entender um pouco mais sobre esta síndrome e minha surpresa foi que não encontrei quase nada e me deparei com a seguinte situação: o que fazer? [...] olhei-a como uma criança normal, no sentido de tratá-la da mesma maneira que as outras. E muitas situações me surpreenderam, pois a cada atividade desenvolvida ela superava todas as expectativas, me mostrando que era capaz de realizar as atividades sem muitas intervenções e que estava compreendendo perfeitamente os acontecimentos ao seu entorno. Seu desenvolvimento foi visivelmente incrível em todos os aspectos. (Pérola² - professora de 2012)

Diante da fala de Pérola, ao procedermos à redução fenomenológica, podemos identificar quatro fases distintas que se interconectam: primeiro se vê como profissional da educação, que possui um papel fundamental na transmissão do conhecimento social e historicamente construído; segundo, recebe uma criança rara; terceiro, a grande dúvida: o que fazer?; quarto, sentindo-se instigada pelo (talvez) não "saber-o-que-fazer" típico de um fenômeno raro, foi buscar conhecimento. Portanto, ao fazermos um paralelo entre aquilo que Pérola vivenciou e aquilo que temos observado no contexto teórico acerca desse processo, podemos salientar que tanto a professora quanto a criança lque chamaremos de Kanga Rosal se apropriaram positivamente desse processo, já que "nada é considerado inato e inerente ao sujeito [...] tudo o que é humano é produção da ação humana" (Diogo; Maheirie, 2007, p. 140) e, consequentemente, causado pelo outro. Além disso,

[...] o fazer humano se dá em meio às contradições que o regulam, e é aí que é preciso compreendê-lo. Esta concepção não visa desresponsabilizar o sujeito por aquilo que de fato faz, mas salientar que um ato (seja do corpo que dança, seja da boca que fala) pode estar relacionado a camadas de significações que se conformam, podem se entrelaçar ou contradizer umas às outras. 0 ato, sem deixar de ser individual, é coletivo: exprime um grupo, mesmo que veio da negação. (Maheirie; França, 2007, p. 5)

Pérola relatou, ainda, que não se conformava com o modo como alguns estudos diziam ser o desenvolvimento de uma criança com tal síndrome. Ela questionava os estudos que lia e realmente achava que era preciso compreender aquele ser humano tão raro, mas nunca encerrá-lo em sua deficiência:

Percebi no decorrer do ano que, mesmo havendo uma criança com um transtorno causado por uma síndrome tão peculiar, devemos olhá-la como olhamos para qualquer outra criança: enxergando nela a capacidade de aprender e construir seus

2. Usaremos nomes de pedras preciosas para nos referirmos aos sujeitos do estudo, por entendermos que todas as pessoas são raras como tais objetos. Tivemos o cuidado de procurar nomes de pedras preciosas que possuíam a letra inicial do nome verdadeiro do sujeito. 
conhecimentos com a mesma vontade, desejo e alegria que a outra. Se eu já tinha comigo a certeza de que todas as crianças são capazes de aprender, não importando sua condição social, física, mental ou mesmo sensorial, com a presença de Kanga Rosa esta afirmação ficou intrínseca em mim [...] (Pérola).

Ao estabelecermos um diálogo entre a fala de Pérola, o contexto da fenomenologia existencial e o pensamento de Vigotski, podemos entender que, realmente, "uma vez integrada num ambiente adequado, a criança sofre rápidas transformações e alterações: esse é um processo surpreendentemente rápido, porque o ambiente sociocultural [...] estimula na criança as formas necessárias de adaptação". (Vigotski, 1996, p. 180)

Nesse contexto, e concordando com Sartre lapud Diogo; Maheirie, 2007, p. 141) quando diz que "[...] o movimento de enriquecimento totalizador [é o] que engendra cada momento a partir do momento anterior", trazemos a fala de Safira, professora de Kanga Rosa no ano de 2013.

0 trabalho com a síndrome de Rubinstein-Taybi, no princípio, parecia assustador, pois tudo que é novo causa insegurança. Porém, no decorrer do ano, e a partir de observações, percebi que a aluna se envolve significativamente em todos os espaços/ tempos do CMEI. [...]. Sendo assim, trabalhar com essa criança está sendo prazeroso e natural (Safira).

0 relato de Safira acerca de Kanga Rosa se aproxima muito daquele de Pérola. Entretanto, percebe-se que Safira foi influenciada pelo processo de descoberta realizado no ano anterior por Pérola. Ou seja, ela não teve que criar do nada, ao contrário, observando devidamente, apropriou-se de um conhecimento preexistente e, a partir daí, trouxe para si o processo de "existencializar" o fenômeno, ao mesmo tempo que se "existencializava”, num processo de ser-sendo para si e para o outro. Fato também percebido na fala da mãe de Kanga Rosa:

Apesar da síndrome dela, ela para mim é normal como qualquer outra criança da idade dela. Hoje ela canta músicas, sabe o alfabeto completo sem olhar as letras, sabe o nome dela, do pai, do irmão, inclusive está me chamando pelo nome agora. Gosta de ir para a escola; no começo do ano [2013], ela chorava porque trocou de professora, até hoje ela fala da tia Pérola. A tia Safira é a atual professora. Ela gosta dos coleguinhas, fala o nome deles em casa, relata o que aconteceu com ela na escola. (Jade - mãe de Kanga Rosal

Observa-se na fala da mãe uma proximidade muito grande com o pensamento de Vigotski (1996, p. 220), quando nos diz que "0 homem é uma criatura social, e as condições socioculturais o modificam profundamente, desenvolvendo toda uma série de novas formas e técnicas em seu comportamento". 
Os relatos destacados nesse breve artigo nos possibilitam reafirmar que nós nos constituímos a partir do olhar e da palavra do(s) outro(s); por isso, somos nós para nós mesmos e para os outros que estão ao nosso redor. Ao acreditarmos nas potencialidades dos sujeitos com ou sem deficiência, e, no caso do nosso estudo, nas potencialidades de um ser tão peculiar, somos levados a afirmar que, ao acreditarmos no potencial do outro, esse outro pode assumir uma série de novas/ outras possibilidades de ação e (interlação. Afinal, como afirma Vigotski (2001), o ser humano é uma forma fluente e influente de transformação de si e do outro. Logo, ao ser significado na escola como um ser que produz história, cultura e conhecimento, influencia o(s) outro(s), pois

Ao mesmo tempo em que esse aluno é uma individualidade, ele é um ser-com, isto é, ele é com pessoas e com coisas. 0 ser-aluno está num devir, é um ser temporal que se preocupa consigo próprio, mas, ao mesmo tempo, toma conhecimento de si mesmo, do mundo e se projeta no futuro. (Martins; Bicudo, 2006, p. 55)

Diante do exposto, mas sem a pretensão de esgotar o assunto, somos levados a enfatizar que as falas dos sujeitos entrevistados acerca do trabalho realizado e do modo como "viam/percebiam/existencializavam" a criança com a síndrome de Rubinstein-Taybi nos conduzem a questionar alguns estudos das características corporais que podem conduzir a uma ideia reducionista acerca das potencialidades do sujeito, dependendo do modo como forem interpretadas, como relatado nas primeiras partes deste estudo, que insistem em dizer o que uma criança com determinada síndrome é capaz ou não de fazer. Ao perceber o sujeito como um ser único em sua existência, como fez/fizeram/fazem Pérola, Safira e Jade, percebe-se o quanto é perigoso encerrar o sujeito em meras convenções médicas e biológicas que desconsideram o caráter criador/criativo e existencial que tem o ser humano.

Neste contexto, o olhar fenomenológico-existencial para Kanga Rosa nos leva a enfatizar que, de acordo com Diogo, Maheirie (2007, p. 144),

0 sujeito se constitui nas relações que estabelece em sociedade, [...]. Para investigar o modo como uma pessoa chega a ser quem ela é, precisamos considerar as múltiplas dimensões que participam da sua constituição. Assim, um sujeito não pode ser visto exclusivamente como produto de suas relações passadas, mas deve também ser compreendido em sua dimensão de futuro (grifos das autoras).

Acreditamos que o campo dos possíveis e dos (im)possíveis compreende uma dimensão de ser-estar-mundo para si e para os outros. E, no contexto escolar comum, diante dessa afirmação e em estreita associação às falas destacadas, somos levados a perceber que o processo de inclusão escolar de uma criança 
com uma síndrome rara na escola comum pode assumir um caráter inovador na medida em que os sujeitos que vivem/pensam tal processo assumem-se como sujeitos da ação pedagógica.

As falas destacadas mostram claramente que a inclusão escolar de uma criança com uma síndrome rara é possível na medida em que este ser é significado como um ser que é para si e para os outros; na medida em que é visto como sujeito cognoscente, aprendende e ensinante; quando os profissionais da educação entendem que todos, independentemente de quaisquer características, são seres únicos em suas existências e, portanto, seres sócio-históricos-culturais; quando as práticas pedagógicas são planejadas, pensadas, observadas, analisadas em função dos sujeitos que compõem o cotidiano escolar; e, por fim, como afirma Sennett (2004, p. 13), “a sociedade moderna carece de expressões positivas de respeito e reconhecimento pelos outros". E é isto o que visualizamos neste estudo: respeito que fez com que a criança fosse vista como ser existente.

Ao pensamos os processos de inclusão escolar de sujeitos com síndromes tão peculiares como as apresentadas no início deste texto, assim como, por exemplo, em relação à Síndrome de Rubisntein-Taiby, numa perspectiva fenomenológicaexistencial, e entendendo que, para a fenomenologia, não há necessidade de uma grande quantidade de sujeitos, mas o que conta é o fenômeno e a experiência em si, podemos pressupor que o sujeito com ou sem deficiência ao ser existenciado pelo outro, tendo sua subjetividade respeitada e valorizada, pode aprender e se desenvolver como qualquer outro sujeito em processo de escolarização. Nesse contexto, salientamos que,

Com a organização correta da vida da criança e a diferenciação moderna das funções sociais, o defeito físico não pode, de maneira nenhuma, vir a ser para o deficiente a causa da completa imperfeição ou invalidez social. (Vigotski, 2001, p. 380-381)

Em que pese à educação comum, a presença de alunos com deficiência ou transtornos globais do desenvolvimento em processo de inclusão, como visto nas falas destacadas, pode desencadear ações extremamente positivas no sentido de levar os profissionais a repensar suas ações no sentido de reorganizar o ambiente educativo com foco no sujeito para além da falta, da deficiência, dos aspectos meramente biológicos, entendendo-os como seres que também produzem história e cultura ao mesmo tempo que se apropriam da(s) história(s) e cultura(s) alheia(s), num processo de educação e reeducação constante, dialético e ininterrupto. Afinal, somos levados a acreditar que "ao acompanharmos as crianças doentes, acabamos vendo que o caminho para a sua correta educação passa pela educação de um meio que lhes ajude a estabelecer os vínculos necessários com ajuda da educação". (Vigotski, 2001, p. 390) 
Uma criança vai se constituindo como sujeito na medida em que se relaciona com as pessoas, com as coisas, com seu corpo e com seu tempo. Apropriando-se de sua cultura, objetiva-se nela. Esta dinâmica origina-se na necessidade do ser humano em criar meios para sobreviver, transformando a si próprio através da atividade. (Diogo; Maheirie, 2007, p. 142)

Em suma, a partir das discussões apresentadas, esperamos contribuir para a problematização das ações pedagógicas com foco na inclusão escolar de sujeitos com deficiência causada por síndromes muitas vezes desconhecidas da grande maioria dos profissionais que estão nas escolas de educação básica comuns. Além disso, esperamos que o olhar fenomenológico-existencial para esses sujeitos, expresso nas falas dos sujeitos do estudo, estimule esses profissionais a ressignificar suas práticas, bem como o olhar para o outro como membro da diversidade humana, para além de convenções engessadas que insistem em dizer quem é e quem não é capaz de aprender.

\section{Referências}

ARTS. Associação Rubinstein-Taybi. <www.artsbrasil.org.br>. Acesso em 21 de mar. de 2013.

ASSIS, Luciana de O. D. Síndrome de Rubinstein-Taybi: estudo de um caso em uma escola regular de ensino de Coronel Fabriciano - MG. 2011. (41 f.). Monografia (Especialização em Desenvolvimento Humano, Educação e Inclusão Escolar) Universidade de Brasília, 2011.

BAPTISTA, Cláudio R. Inclusão e escolarização: múltiplas perspectivas. Porto Alegre: Mediação, 2006.

BEYER, Hugo O. Da integração escolar à educação inclusiva: implicações pedagógicas. In: BAPTISTA, Cláudio R. Inclusão e escolarização: múltiplas perspectivas. Porto Alegre: Mediação, 2006, pp. 73-82.

BRASIL. Política Nacional de Educação Especial na Perspectiva da Educação Inclusiva. Brasília: MEC/SEESP, 2008.

BRASIL. Constituição Federal de 1988. Brasília: Senado Federal, 1988.

BRASIL. Lei de Diretrizes e Bases da Educação Nacional. Lei 9394. Brasília: Senado Federal, 1996.

BRASIL. Resolução CNE/CEB 04/2009. Brasília: MEC/SEESP, 2009.

CAMPOS, Shirley de. Síndrome de Rubinstein-Taybi. 2003. Disponível em: <www. drashirleydecampos.com.br>. Acesso em: 22 mar. 2013.

CEPCARIRI. 0 que é fenomenologia-existencial. Disponível em: <www. cepcariri. blogspot.com.br>. Acesso em: 21 mar. 2013. 
DIOGO, Maria F.; MAHEIRIE, Kátia. Uma breve análise da constituição do sujeito pela ótica das teorias de Sartre e Vygotski. Aletheia, n. 25, jan./jun. 2007, pp. 139151.

DRAGO, Rogério. Educação infantil e educação inclusiva: um olhar sobre o trabalho com crianças com deficiência. In: ROCHA, Eloísa A. C.; KRAMER, Sonia. Educação infantil: enfoques em diálogo. São Paulo: Papirus, 2011b, pp. 259-276.

DRAGO, Rogério. Inclusão na educação infantil. Rio de Janeiro: WAK, 2011.

DRAGO, Rogério. Síndromes: conhecer, planejar e incluir. Rio de Janeiro: WAK, 2012.

DRAGO, Rogério. Estudos e pesquisas sobre síndromes: relatos de casos. Rio de Janeiro: WAK, 2013.

GIL, Antônio. C. Métodos e técnicas de pesquisa social. São Paulo: Atlas, 1994. JANUZZI, Gilberta. A Educação do deficiente no Brasil: dos primórdios ao início do século XXI. 2.ed. São Paulo: Autores Associados, 2006.

MAHEIRIE, Kátia; FRANÇA, Kelly B. Vygotski e Sartre: aproximando concepções metodológicas na construção do saber psicológico. Psicologia \& Sociedade, v. 19, n. 1, pp. 1-9, jan.-abr. 2007.

MARTINS, Joel; BICUDO, Maria A. V. Estudos sobre existencialismo, fenomenologia e educação. São Paulo: Centauro, 2006.

MARTINS, Regina H. G.; BUENO, Elaine C.; FIORAVANTI, Marisa P. Síndrome de Rubinstein-Taybi: anomalias físicas, manifestações clínicas e avaliação auditiva. Revista Brasileira de Otorrinolaringologia, São Paulo, v. 69, n. 3, pp. 1-6, maio-jun. 2003.

MAZZOTTA, Marcos J. S. Educação especial no Brasil: história e políticas públicas. São Paulo: Cortez, 2001.

MENDES, Enicéia G. Perspectivas para a construção da escola inclusiva no Brasil. In: PALHARES, Marina S.; MARINS, Simone. Escola Inclusiva. São Carlos: EduFSCar, 2002, pp. 45-60.

MICHEL, Maria H. Metodologia e pesquisa científica em Ciências Sociais. São Paulo: Atlas, 2009.

PINEL, Hiran. A teoria dos modos de ser sendo si mesmo [com o outro] no cotidiano do mundo: um discurso fenomenológico-existencial. Vitória: UFES/CE/PPGE, 2005. PINEL, Hiran. Psicologia da educação. Vitória: Neaad/UAB, 2004.

PINEL, Hiran. Psicopatologia do escolar: nominalismo, niilismo e transparência. 2011. Disponível em: <http://hiranpinel.blogspot.com> Acesso em: 21 mar. 2013. PRIETO, Rosângela G. Atendimento escolar de alunos com necessidades educacionais especiais: um olhar sobre as políticas públicas de educação no Brasil. In: ARANTES, Valéria A. (Org.). Inclusão escolar. São Paulo: Summus Editorial, 2006, pp. 31-73. SENNETT, Richard. Respeito: a formação do caráter em um mundo desigual. Rio 
de Janeiro: Record, 2004.

VIGOTSKI, Lev S. Psicologia pedagógica. São Paulo: Martins Fontes, 2001.

VIGOTSKI, Lev S. Estudos sobre a história do comportamento: o macaco, o primitivo e a criança. Porto Alegre: Artes Médicas, 1996.

Recebido em fevereiro de 2014

Aprovado em maio de 2014

Rogério Drago é doutor em Ciências Humanas - Educação pela Pontifícia Universidade Católica do Rio de Janeiro (PUC-Rio) e professor adjunto do Departamento de Teorias do Ensino e Práticas Educacionais e do Programa de Pós-Graduação em Educação do Centro de Educação da Universidade Federal do Espírito Santo. E-mail: rogerio.dragolagmail.com

Hiran Pinel é doutor em Psicologia pelo Instituto de Psicologia da Universidade de São Paulo (IP-USP) e faz Residência Pós-Doutoral na Faculdade de Educação da Universidade Federal de Minas Gerais (FAE-UFMG). Professor Associado III da Universidade Federal do Espírito Santo. E-mail: hiranpineldig.com.br 